\title{
Uma genealogia imunitária: a bioética e a busca da autoconservação humana
}

\section{Resumo}

Explorando brevemente o contexto histórico e os principais tópicos da bioética, o artigo argumenta que existe um modo de enfrentamento próprio da disciplina, caracterizado por um mecanismo que opera visando à autoconservação humana a partir da discussão sobre os critérios de qualificação do humano. Este mecanismo, central e unificador à heterogeneidade de concepções e perspectivas morais da bioética, é contextualizado em um horizonte de sentido mais amplo, que Esposito denomina paradigma imunitário. Finalmente, são delineadas algumas possibilidades de contribuição que esta chave interpretativa imunitária pode oferecer à bioética, no que tange às suas tensões internas e funções descritiva e normativa.

Palavras-chave: Bioética. Biopolítica.

\section{Resumen}

\section{Una genealogía inmunitaria: la bioética y la búsqueda de la auto-conservación humana}

Explorando brevemente el contexto histórico y los principales temas de la bioética, el artículo sostiene que hay una manera de enfrentamiento propio de la disciplina, que se caracteriza por un mecanismo que opera con el objetivo de auto-conservación humana a partir de la discusión de los criterios de calificación del humano. Este mecanismo, central y unificador de la heterogeneidad de conceptos y perspectivas morales de la bioética, se contextualiza en un horizonte más amplio de significado, que Esposito denomina paradigma Inmunitario. Por último, son indicadas posibles contribuciones que esta clave interpretativa inmunitaria puede ofrecer a la bioética, en lo que respecta a sus tensiones internas y funciones descriptiva y normativa.

Palabras-clave: Bioética. Biopolítica.

\section{Abstract}

\section{An immunitary genealogy: bioethics and the pursuit of human self-preservation}

Briefly exploring the historical context and the main topics of bioethics, this article argues that the subject has its own way of coping, which is characterized by a mechanism that operates in pursuit of human selfpreservation through the continue discussion on the attributes that define humans. This mechanism - which is central and unifies the discipline's heterogeneity of concepts and moral perspectives - is contextualized in a broader horizon of meaning, which Esposito calls the paradigm of immunization. Finally, the article indicates possible contributions that the immune interpretive key can offer to bioethics, regarding the tensions within the field and the descriptive and normative functions of bioethics.

Key words: Bioethics. Biopolitics.

Doutora pyrrho.monique@gmail.com - King’s College London, Londres, Reino Unido/Universidade de Brasília, Brasília/DF, Brasil.

\section{Correspondência}

Colina Bloco I Apt ${ }^{\circ}$ 101. Campus Universitário Darcy Ribeiro. Asa Norte CEP 70904-109. Brasília/DF, Brasil.

Declara não haver conflito de interesse. 
A bioética está em crise e, a não ser que repense sua prática, não terá futuro. Esta é uma afirmação cada vez mais comum na literatura. Um dos motivos dessa crise seria a relação estabelecida com o saber biomédico, que faz com que a bioética tenha seu poder crítico diminuído ${ }^{1-3}$. Em outras leituras, é a tendência à especialização do campo, impulsionada pelo surgimento cada vez mais frequente de novos avanços tecnocientíficos, que ameaça o futuro da bioética ${ }^{4}$. Um olhar para a história da disciplina, porém, mostra que a crítica ao lapso entre a velocidade da produção do conhecimento e a capacidade de examiná-lo eticamente contextualizam a bioética desde seu surgimento.

A obra Bioethics: bridge to the future, o primeiro livro sobre a disciplina, propõe justamente um campo de conhecimento que visa servir de instrumento para a superação do lapso de comunicação, funcionando como ponte entre ciência e humanidades ${ }^{5}$. Nessa perspectiva, a bioética busca lidar com um problema premente: sem o necessário diálogo com as humanidades, o crescente e inexorável desenvolvimento científico e seu grande potencial de transformação do meio ambiente representam ameaça à humanidade. Então, para garantir a conservação humana o pensamento bioético teria como fundamento a adoção do critério da sobrevivência como guia de ação e a discussão sobre que tipo de sobrevivência devemos defender ${ }^{6}$.

Sob o ponto de vista de Potter, a tarefa da disciplina seria refletir moralmente sobre o progresso científico, mas com um propósito muito claro: a conservação da espécie humana. Mais ainda: já que sua ação não visaria à mera sobrevivência, torna-se necessário discutir o que qualificaria essa sobrevivência ${ }^{7}$. Assim, a bioética figura como um mecanismo de autoconservação humana, cuja operação pressupõe a contínua discussão sobre o que é o humano.

Contudo, quase simultaneamente à proposta de Potter, o termo bioética surge com outra conotação. Meses após o lançamento do livro de Potter ${ }^{5}$, é fundado o Kennedy Institute of Ethics. Desconsiderando, aparentemente, a preocupação mais genérica com a conservação da espécie humana, o instituto, sediado na Universidade de Georgetown, tinha como objetivos a pesquisa e o debate sobre problemas bioéticos, entendidos como os dilemas médicos concretos relacionados à área biomédica ${ }^{8}$. Oito anos mais tarde, com a publicação da primeira edição de Principles of biomedical ethics ${ }^{9}$, a bioética se estabelece hegemonicamente no âmbito acadêmico como sinônimo de ética biomédica.
Parece haver - ao menos - duas concepções bastante distintas da disciplina, que se desenvolvem paralelamente. Para a mais predominante delas, a bioética dedica-se à reflexão dos problemas éticos resultantes da prática biomédica e a contribuição de Potter representa apenas um aspecto histórico de pouca influência prática. Paralelamente, há uma perspectiva que ressalta a pertinência e a importância dos insights de Potter para a reflexão de questões bioéticas globais ${ }^{10,11}$.

Em pouco tempo, essa divergência de perspectivas passa a fazer parte de diversas narrativas históricas sobre a disciplina ${ }^{8}$. Em contraste, o presente texto argumentará que essas concepções, aparentemente tão diversas entre si, aproximam-se por compartilhar um mesmo modus operandi. Explorando brevemente o contexto histórico de seu surgimento e os principais tópicos da disciplina, pretende-se desvelar indícios de um modo de enfrentamento próprio da bioética, caracterizado por um mecanismo que opera visando à autoconservação humana a partir da discussão sobre os critérios de sua qualificação.

O papel, ao mesmo tempo central e unificador, que este mecanismo exerce para a disciplina será analisado de forma a localizar o fazer bioético em um horizonte mais amplo que Esposito ${ }^{12}$ denomina paradigma imunitário. Finalmente, o artigo buscará ilustrar as possibilidades de contribuição que esta chave interpretativa da imunidade oferece à bioética.

\section{Bioética: em busca de um fio comum}

A existência de muitas e diferentes narrativas sobre as origens da bioética é alvo de numerosos esforços de sistematização ${ }^{13}$. Até sua origem norteamericana, tida como o fato comum em meio a tantas versões ${ }^{14}$, encontra argumentos contrários. Recentemente, tem crescido o número de autores que creditam a primeira menção do termo bioética ao filósofo alemão Fritz Jahr, em 1927. Nessa perspectiva, Jahr teria sido um precursor da bioética não só pelo uso pioneiro do termo, mas também por suas intuições sobre a complexidade dos desafios morais impostos pelo desenvolvimento científico ${ }^{15-18}$.

Para além da discordância sobre a origem do termo e da própria bioética, as listas de eventos, estudos e autores apontados como pioneiros também variam substancialmente. Esta grande quantidade de narrativas sobre disciplina tão recente pode ser atribuída à tentativa coletiva de estabelecer e legitimar academicamente uma disciplina de caráter 
complexo ${ }^{14}$. De fato, as controvérsias históricas são apenas uma faceta da complexidade do fenômeno bioético.

Em busca de soluções morais para as questões que enfrenta, o fazer bioético assume tanto um caráter de discurso público, na arena política, quanto de campo interdisciplinar, no ambiente acadêmico. Consequentemente, são envolvidas diferentes perspectivas e áreas de conhecimento que, por sua vez, variam quanto aos propósitos e tipos de contribuição que podem oferecer ao debate bioético ${ }^{19}$. Muito provavelmente, no entanto, a diferença de concepções mais notória é aquela entre a bioética global de Potter e a do legado do Instituto de Georgetown. Essa distinção, ao que parece, delinearia uma gama diversa de objetos de estudo, fundamentos e abordagens teóricas.

Por um lado, quando concebida como sinônimo de ética biomédica, a bioética possui enfoque na saúde humana (em contraste a uma perspectiva mais ecológica e global) e nos aspectos morais da terapêutica, da pesquisa e das políticas na área da saúde. Alguns dos principais temas abordados seriam: aborto; clonagem; engenharia e melhoramento genético; comercialização de órgãos e tecidos humanos; eutanásia; pesquisa e terapia com células-tronco; tecnologias reprodutivas; pesquisas clínicas; direitos dos pacientes e consentimento informado; e alocação de recursos em saúde ${ }^{20}$. Por outro, ainda que não compartilhem necessariamente todos os pressupostos de Potter, as presentes sistematizações sobre a bioética global se contrapõem a concepções compartimentadas da ética e propõem uma integração interdisciplinar com vistas ao enfrentamento moral de problemas globalizados. Nessa perspectiva, em adição aos tópicos biomédicos, discutem-se temas como ecossistema e biodiversidade; usos ambíguos dos achados científicos; conhecimento, poder e corrupção; e pobreza ${ }^{21}$.

À primeira vista, o fio comum que une aborto, eutanásia e alocação de recursos em saúde parece epistemicamente vago. Por sua vez, compreender qual é o escopo da bioética global parece difícil, tamanha sua abrangência. Haveria algo a mais em comum entre essas temáticas biomédicas que pudesse servir de critério de inclusão (ou exclusão) para outros problemas futuramente enfrentados nesse âmbito? O que faria de uma questão global um problema bioético global? Isso equivale a se perguntar, enfim, se seria possível identificar alguma conexão entre as duas bioéticas, além do nome.

A ênfase nas divergências internas à bioética culmina justamente na pergunta que move esse artigo: há, afinal, um fio comum que possa unificar essa heterogeneidade de narrativas, perspectivas e objetos em um mesmo campo de saber?

A resposta a esta pergunta é positiva e o argumento a ser desenvolvido é que aquilo que engendra na mesma tessitura concepções tão heterogêneas sob o escopo da disciplina é um modus operandi específico. Este é direcionado a uma finalidade: a conservação humana; e movido por uma dinâmica: a qualificação de seus critérios de operação. Em outras palavras, em comum, as diferentes noções de bioética são caracterizadas por seu objetivo de conservar o humano e pela constante necessidade de pautar o que qualifica e, em última ordem, define essa humanidade a ser preservada. Esse mecanismo não somente serve de conexão teórica para os diferentes objetos da disciplina, mas também possui reflexos no tipo de análise que a bioética oferece sobre eles.

Para desenvolver esta tese, inicialmente, é destacado o papel determinante que o tema da ambiguidade do conhecimento científico desempenhou para o processo de gênese da bioética. Em um segundo momento, o texto apontará como essa percepção de risco/ameaça à sobrevivência humana implicou que a disciplina se desenvolvesse em torno da questão da conservação humana e dos seus mecanismos de qualificação.

\section{Ambiguidade do conhecimento científico}

No período pós-Segunda Guerra Mundial, o desenvolvimento científico passa a ser objeto de reflexão ética não por encontrar-se em crise, mas porque não é possível prever plenamente os riscos de seus sucessos e realizações. Precisamente, são descobertas científicas bem-sucedidas, como novos medicamentos com efeitos colaterais desconhecidos, por exemplo, que revelam o caráter ambíguo do empreendimento científico, capaz tanto de meIhorar as condições de vida humana quanto de lhe ameaçar a sobrevivência. Percebe-se, então, que o desenvolvimento científico, justamente pelo vulto de suas realizações, pode desafiar conviç̧ões morais e produzir riscos inesperados ${ }^{22}$.

Costuma-se afirmar que esse tipo de preocupação sobre a sobrevivência da espécie é próprio da noção de Potter e pouco teria contribuído para a concepção atual predominante da bioética ${ }^{20}$. Essa afirmação não considera, porém, que a ética biomédica também passou por um momento de intensas discussões sobre o caráter moralmente ambíguo do 
conhecimento científico. O próprio Hellegers, talvez o mais emblemático dos fundadores do Kennedy Institute of Ethics, descreveu a bioética como uma maneira de tematizar os impactos da tecnologia médica, que atingiria moralmente não somente os doentes, mas toda a humanidade ${ }^{8}$.

Jonsen ${ }^{23}$ reforça a importância dessa preocupação sobre a sobrevivência humana para o estabelecimento da bioética no âmbito biomédico. A criação dos institutos norte-americanos dedicados ao tema, como o Instituto de Georgetown e o Hastings Center, é subsequente a um período de intensos debates sobre o impacto do desenvolvimento científico na sobrevivência humana.

A percepção da ambiguidade do conhecimento científico, portanto, constituía um denominador comum entre as diferentes concepções da bioética. Este fato não escapa à percepção de Potter e, baseado nesse entendimento, ele mesmo contradiz a independência entre a vertente biomédica e a bioética global. Conferência da American Association For Cancer Research aponta o Instituto de Georgetown como prova do sucesso que a bioética havia atingido no mundo acadêmico. Na oportunidade, cita diretamente o trecho em que Hellegers afirma que a bioética não tem a função de restringir a ciência, mas sim de relembrar que a ciência e a medicina estão a serviço do homem. Na verdade, ainda que Potter faça críticas à compartimentalização da disciplina, para ele a bioética médica não está em desacordo com sua própria noção, já que partilha o objetivo de balizar moralmente os usos do conhecimento científico ${ }^{24}$.

\section{Autoconservação humana e critérios de qua- lificação}

Diante da ambiguidade do conhecimento científico e da ameaça que esta representa à humanidade, a sobrevivência humana e o debate sobre quais são as características (humanas) que desejamos conservar tornam-se centrais para a bioética global ${ }^{6}$. Por sua vez, a ética biomédica, cujo alcance e propósitos se redefinem após uma série de conferências na década de 60, enfrenta o mesmo tipo de questão. A primeira delas, intitulada The great issues of conscience in modern medicine, nas palavras de Jonsen, pautava não apenas a questão da sobrevivência ou a extinção do homem, mas que tipo de sobrevivência? Um futuro de que natureza? ${ }^{23}$

Para a perspectiva biomédica, o desenvolvimento científico impunha desafios à sobrevivência humana que iam além da ameaça nuclear e do esgotamento de recursos ambientais. O incremento tecnológico dos meios de manutenção da vida, como a invenção de aparelhos de diálise artificial e os transplantes de órgãos, impôs a necessidade de rediscutir os parâmetros científicos e morais para determinação da sobrevida e da morte humanas ${ }^{23}$. Desta forma, percebe-se que o caráter ambíguo do desenvolvimento tecnocientífico, quer em dimensão global, quer no âmbito da prática biomédica, apresenta a questão da sobrevivência e a determinação de parâmetros para sua conservação como dilemas morais para a bioética.

Isto ocorre porque, enquanto ação antrópica, a ciência serve como meio de autoconservação humana, pois pretende prolongar e melhorar as condições da vida humana individual e coletivamente, mas seus esforços tomam o próprio humano e seu entorno como objetos de intervenção e alteração. Em consequência, não somente surgem novos riscos para o homem, mas a própria percepção sobre quais são os atributos que o definem e devem, assim, ser protegidos é posta em discussão.

Para assegurar que o desenvolvimento científico configure meio para a autoconservação da humanidade e não ameaça a esta, a bioética enfrenta a tarefa de discutir os valores morais a defender, perguntando-se continuamente o quê exatamente pretende conservar. É esta discussão que está por trás, por um lado, da busca por parâmetros científicos e morais de definição do início e do fim da vida e, por outro, do debate sobre os valores a serem respeitados durante a intervenção médica, como a autonomia, a dignidade etc. Esse contexto inicial é determinante para imprimir um caráter para a bioética, para desenvolver o mecanismo comum que unifica concepções diversas de bioética e pelo qual enfrenta os dilemas morais que o desenvolvimento científico impõe enquanto mecanismo de autoconservação humana.

Contudo, a própria bioética constitui mecanismo de autoconservação. E para realizar esta tarefa precisa discutir continuamente o que caracteriza essa humanidade que se está tentando conservar. Logo, percebe-se que a função normativa da bioética é exercida justamente a partir da discussão contínua sobre as zonas de indistinção, as fronteiras móveis, entre o sujeito e seu substrato biológico, entre indivíduo e comunidade. A análise bioética, com o objetivo da autoconservação humana, implica em reflexão constante sobre as categorias usadas para definir o status dos organismos viventes, inclusive aquele do ser humano. 


\section{Paradigma imunitário}

A discussão sobre os atributos que qualificam o humano e o deslocamento contínuo das zonas de distinção entre o humano e não humano constituem uma dinâmica presente na tradição ocidental, ao menos desde a clássica visão aristotélica do ser humano como animal político (zoon politikon). O deslocamento e reposicionamento desta cisão e suas articulações funcionam como instância de decisão incessantemente atualizada sobre o que é humano ${ }^{25}$.

Efetivamente, desde seu princípio, a política se fundamenta nesta disposição de definir a identidade humana por contraste, ou seja, em oposição àquilo que não é humano. Delimitado como espaço de exclusão da zoé (uma vida orgânica como aquela dos animais), o âmbito político se estabelece como o lugar de realização de uma vida qualificada característica e exclusiva dos humanos, bíos. No entanto, esta fronteira móvel entre humano e não humano, entre mera vida (zoé) e vida qualificada (bíos), sofre uma transformação que coincide com o próprio surgimento da modernidade. A partir de então, a vida nua (zoé), cuja exclusão constituía a condição fundante para a política, passa a ocupar o papel central nas relações de poder, inaugurando uma configuração biopolítica da sociedade ${ }^{26}$.

A biopolítica é marcada exatamente por estratégias de poder baseadas no controle e reprodução da vida e, consequentemente, pela ascensão do corpo biológico ao centro da vida política ${ }^{27}$. Da configuração biopolítica, resultam o incremento do prestígio social do conhecimento científico, principalmente aquele biomédico, e o posterior surgimento da biotecnociência, um dos principais objetos de reflexão da bioética ${ }^{28}$. Resultante dos progressos do campo biológico, principalmente nas subáreas da biologia molecular, da bioquímica, da genética e das neurociências, a biotecnociência representa o esforço de superação das limitações impostas pela estrutura orgânica da vida e compreende o conjunto de ferramentas teóricas e práticas que visam à meIhoria das condições de vida humana ${ }^{28}$.

Como um saber-fazer guiado para a intervenção técnica em seres e processos vivos, a biotecnociência e seus aspectos morais têm caráter proeminentemente biopolítico. O prestígio social do conhecimento biomédico e de seu projeto de prolongar e melhorar a vida humana têm resultado em uma compreensão do homem predominantemente baseada em seus componentes biológicos, disponíveis à intervenção biotecnocientífica. Neste quadro, a bioética serviria como mecanismo de oposição, uma forma de resistência aos efeitos negativos da biopolítica, revelando e combatendo as consequências morais da redução da humanidade a seus dados biológicos ${ }^{29}$.

Para oferecer resistência aos resultantes indesejáveis da biotecnociência, no entanto, é preciso relembrar que seu caráter moralmente ambíguo, que conserva e ameaça ao mesmo tempo, deriva de uma biopolítica em si ambivalente. Por um lado, a nova ordem biopolítica é definida em contraposição ao poder soberano derivado da prerrogativa da morte. Nessa perspectiva, a conservação da vida assume papel político central e a promoção da saúde e dos direitos individuais tornam-se fortes mecanismos de subjetivação. Por outro, a redução do homem a sua dimensão biológica contextualiza a instrumentalização tecnocientífica do homem, o racismo e, por fim, o nazismo ${ }^{30}$.

Segundo Esposito ${ }^{31}$, a biopolítica é atravessada por uma antinomia sobre a qual Foucault jamais se posicionou definitivamente, representando-a ora como um mecanismo de subjetivação e reprodução da vida, ora como de anulação e morte humana. É desta indecisão, ainda segundo Esposito ${ }^{31}$, que deriva o contraste entre a conotação positiva da biopolítica de Hardt e Negri ${ }^{32}$, que a entendem como forma de resistência ao poder soberano (do Império), e aquela negativa de Agamben ${ }^{26}$, que a identifica como continuidade do poder soberano.

A indecisão de Foucault e a divergência na sua recepção, porém, não derivam somente de uma dúbia articulação histórica entre o poder soberano e a biopolítica. Para Esposito, o motivo da antinomia é a própria relação entre a vida e a política, pensadas por Foucault como categorias distintas que se articulam, dando origem à configuração biopolítica. Por esta razão, a imunidade é proposta por Esposito como uma chave interpretativa que explica a indissociável conexão entre elas e, consequentemente, o caráter intrinsecamente antinômico da biopolítica. A imunidade, nesta perspectiva, fundamenta o tipo de relação de mútua dependência estabelecida entre vida e política, segundo a qual o poder sempre tem a vida como substrato e a vida necessita das relações de poder para se manter. Ao contrário de ressaltar o momento em que vida e política se interceptam, a categoria de imunidade destaca a dinâmica conservativa que caracteriza a relação desde sempre necessária entre vida e política ${ }^{31}$.

Mais precisamente, a autoconservação imunitária se caracteriza por uma proteção negativa da vida, ou seja, por um movimento antinômico e artificial que, pretendendo a conservação da vida, 
contradiz os meios autoconservativos naturais. Elemento indispensável na história humana, a autoconservação, neste sentido, se realiza apenas com a condição de uma negação protetiva de mecanismos naturais de preservação e, consequentemente, inaugura a técnica como meio de garantir a conservação de uma vida que resulta sempre alterada, irremediavelmente artificial. A qualidade negativa da proteção imunitária reside exatamente na ideia de que o modo peculiar de autoconservação da espécie humana deriva da restrição e privação de parte de sua própria constituição ${ }^{33}$.

A noção de privação está presente já na origem etimológica da palavra imunidade (immunitas), estabelecida em negação à comunidade (communitas). Enquanto a communitas é vinculada por um munus - uma obrigação de doação recíproca e, portanto, nunca apropriada -, a imunidade é a privação da obrigatoriedade do dom, sempre acompanhada por mecanismos de defesa contra os efeitos expropriativos da comunidade. A imunidade pressupõe a existência do próprio que precisa ser defendido de sua aniquilação, ou seja, da expropriação representada pelo contato com o outro ${ }^{12}$.

Esta breve excursão etimológica desvela não somente o caráter negativo e restritivo dos mecanismos imunitários de autoconservação humana, mas também a influência estrutural que a resultante relação entre indivíduo e comunidade exerce no desenvolvimento da lógica individualística e privatística da modernidade ${ }^{12}$. O importante papel que o conceito de imunidade tem para a medicina e para o direito irradia-se para as mais diferentes áreas, desde as relações internacionais com as imunidades diplomáticas até a ciência da computação com os antivírus informáticos. Esse conceito, segundo Esposito ${ }^{34}$, é fundamental para compreender a modernidade e, embora possua acepções diversas a depender da área, remete a uma necessidade cada vez mais antecipada de proteção de um risco/ameaça ao qual os demais estão expostos.

Se a imunidade marca desde sempre as formas de conservação da vida, o paradigma imunitário, ou da imunização, é uma sistematização teórica de um horizonte inaugurado com a modernidade. Ainda que a necessidade autoconservativa seja um pressuposto político, porque sociedade e mecanismos de defesa são historicamente indissociáveis, somente a modernidade coloca a necessidade de autoconservação da vida individual como seu problema central e ergue em torno desta questão seus aparatos institucionais ${ }^{31}$. Para constituir o que chamamos de sujeito moderno, por sua vez, a imunida- de constrói uma solução de continuidade, um vazio artificial na expressão de Esposito ${ }^{12}$, que ao mesmo tempo separa e coloca em relação o indivíduo e a comunidade, o próprio e o outro.

Nessa perspectiva, aquilo que é assumido como centro da política moderna, submetido às ações autoconservativas biopolíticas, não é uma mera vida zoé, puramente natural ou biológica, nem, a bem ver, uma forma de vida política, como a concepção clássica de bíos, mas a vida que se situa precisamente no ponto em que essa distinção se torna difusa e perde o significado ${ }^{31}$. A vida da biopolítica é uma vida permanentemente imunizada e em contínuo deslocamento na zona de indistinção entre bíos e zoé, entre o humano e o não humano, entre o próprio e o outro. É exatamente neste vazio artificial, nesta zona de indistinção, que opera o "dispositivo da pessoa": um mecanismo de decisão dos atributos de humanidade ${ }^{35}$.

Esse dispositivo adquire sua expressão atual com a revitalização da categoria de pessoa após a II Guerra Mundial. Naquela ocasião, a subtração do estatuto de cidadão a inteiros grupos étnicos na Alemanha nazista os colocou em condições de subumanos. Desse modo, o revigoramento da categoria serviu para fornecer universalidade maior do que aquela de cidadão, preenchendo conceitualmente o hiato entre cidadão, sujeito de direitos em uma determinada nação, e indivíduo, enquanto condição universalizável do homem. Buscava-se criar uma relação de implicação direta entre a humanidade do indivíduo e o seu direito de possuir direitos ${ }^{35}$.

Mais do que um aspecto jurídico, esta retomada dos pressupostos humanistas foi uma resposta às trágicas consequências do achatamento do humano aos seus dados biológicos. Rebatendo a negação nazista de qualquer elemento que transcendesse a vida biológica humana, a revitalização da categoria de pessoa humana pretendia reconhecer a existência de algo que adere ao ser vivente e lhe muda o status, lhe confere um valor incontroverso e inviolável ${ }^{35}$.

A chave para compreender o que Esposito ${ }^{35}$ chama de dispositivo da pessoa é justamente essa ideia de aderência. Para caracterizar essa percepção, são retomadas as origens romanas da palavra persona, a máscara de função performativa que adere ao rosto do ator, sem se fundir com ele. A apropriação do conceito pela tradição cristã, segundo o autor, aprofunda ainda mais a ideia de aderência, já que na tradição cristã, por quanto indissoluvelmente ligada a um corpo vivente, a pessoa não coincide integralmente com ele e, inversamente, encontra o 
seu elemento mais intrínseco precisamente naquela não coincidência que lhe consente o trânsito para a vida ultraterrena ${ }^{35}$.

A categoria de pessoa, assim, assenta-se nesta não coincidência entre o sujeito e o substrato biológico que o sustenta. Embora tenha sido retomada justamente para evitar a animalização/reificação humana experimentada durante o nazismo, a categoria acaba produzindo um efeito diverso do esperado. Para Esposito ${ }^{35}$, por ser concebida como algo que adere, mas que não se confunde com o corpo biológico, o conceito de pessoa acaba por resultar no oposto de sua aspiração à integridade, produzindo um indivíduo cindido. Em vez de abolir a divisão entre o homem e animal, acaba por implicar em uma introjeção desta perspectiva, que era social, no interior de cada indivíduo. Retoma-se, então, o mote aristotélico do homem como animal racional.

Consequentemente, somente recebe o status de pessoa aquele, dentre os animais, capaz de racionalmente dominar seu corpo biológico e sua animalidade-e, em tempos biotecnológicos, dispor deles. É justamente esta cisão que confere mobilidade às definições dos organismos. $O$ dispositivo da pessoa consistiria, portanto, em um mecanismo imunitário que opera normativamente na zona de indistinção entre o corpo e o sujeito. Por meio de um deslocamento contínuo das fronteiras categoriais, o dispositivo define o status dos seres viventes entre os extremos de animalização e personalização ${ }^{35}$.

O dispositivo da pessoa provoca, consequentemente, dentro do mesmo indivíduo, efeitos de personalização - de sua parte racional - e de despersonalização - de sua parte corpórea, assim animalizada. O domínio que exerce sobre sua parte corpórea confere, simultaneamente, ao indivíduo seu status de pessoa, e ao seu corpo o status de coisa apropriável e disponível para seu domínio e intervenção ${ }^{35}$. Este mecanismo, denominado dispositivo da pessoa, é determinante para o referencial dos direitos humanos e contextualiza historicamente o surgimento da bioética. Por esse motivo, torna-se um elemento central e unificador para posições heterogêneas e aparentemente contrapostas na disciplina.

Nessa perspectiva, a própria existência da bioética enquanto espaço de debate moral deriva da cisão, operada historicamente pelo dispositivo da pessoa, entre pessoa e corpo, que reifica o último. Dessa maneira, os temas que a bioética toma para si são resultantes morais do intento de autoconservação humana por parte da ciência, que propõe intervir sobre o corpo. Consequentemente, no enfrentamento desses temas, tanto a defesa da qualidade ou da sacralidade da vida são posições no debate bioético que discordam quanto a quem pertence o corpo, mas não quanto ao seu caráter de algo apropriável. Nas palavras de Esposito, sejam aqueles que defendem para si a disponibilidade do próprio corpo - para melhorá-lo, modificá-lo, ou ainda para alugá-lo, vendê-lo, suprimi-lo - sejam aqueles que o declaram indisponivel porque propriedade intangível de Deus, do Estado ou da natureza, devem pressupor a sua tradução em coisa. Somente porque reportada antecipadamente à categoria de res extra commercium, a vida humana é declarada sagrada para uns e qualificada para outros ${ }^{35}$.

Assim, toda a discussão bioética, quer aquela de vertente laica ou católica, e suas temáticas sobre o estatuto moral de partes ou do humano como um todo, remetem ao dispositivo da pessoa. O espaço normativo ocupado pela bioética parece justamente surgir do vazio inaugurado pelo paradigma imunitário. Por conseguinte, a cisão operada pelo dispositivo da pessoa, durante uma modernidade altamente tecnicizada, não somente torna o indivíduo separado de seu próprio corpo, mas o torna disponível a intervenções e melhoramentos ${ }^{35}$.

Consequentemente, percebe-se que o uso do paradigma imunitário como chave interpretativa serve como instrumento adicional para a compreensão e análise da ambivalência biopolítica da biotecnociência e suas repercussões para a bioética. Por um lado, a biopolítica confere papel central ao corpo na modernidade. Por outro, esse mesmo corpo é apropriado e disponibilizado para intervenção. A biotecnociência, como mecanismo de autoconservação imunitária, atua de forma a intervir e transformar a dimensão biológica que, a partir da configuração biopolítica da modernidade, define o homem. Como resultante, os atributos de humanidade, ou seja, aqueles que qualificam o homem enquanto tal, tornam-se flutuantes e indistintos abrindo espaço para uma gradação de estágios intermediários entre o humano e o não humano, entre eles o nãoainda-pessoa, o não-plenamente-pessoa, e ainda o não-mais-pessoa. É justamente entre essas barreiras móveis que a bioética tem exercido sua função normativa, discutindo continuamente esses estatutos ${ }^{35}$.

A bioética parece, deste modo, agir como um mecanismo de autoconservação de segundo nível, pretendendo conservar a humanidade dos efeitos negativos dos mecanismos imunitários providos pelo artifício tecnocientífico. Seu espaço normativo parece ter origem nesta complexa dinâmica autoconservativa e ser exercido justamente quando o próprio atributo de humanidade está em discussão. 


\section{Considerações finais}

A breve genealogia imunitária da bioética aqui esboçada desvela que a percepção de ameaça despertada pelo desenvolvimento tecnocientífico representa mais do que uma preocupação inaugural delimitada historicamente. Esse contexto propulsor imprime características permanentes e específicas no enfrentamento bioético de desafios morais. Como elemento unificador das distintas concepções e perspectivas bioéticas, figura o intento de proteger a humanidade da ameaça relacionada a seus próprios esforços de preservação. Portanto, o fio comum que perpassa a bioética consiste em sua atuação como mecanismo imunitário de segundo nível.

A proposta de compreensão da imunidade como uma chave interpretativa tanto do paradigma biotecnocientífico como da bioética, no entanto, não se constitui em um empreendimento somente epistêmico. Há, ao menos, três frentes em que esta proposta pode se demonstrar promissora para a bioética. Primeiramente, encarar a diversidade característica da bioética a partir de um mecanismo comum pode ser um instrumento para refletir e redirecionar as tensões internas ao campo, contribuindo para enfrentar pressões de fragmentação e subespecialização. Em segundo lugar, a função de autoconservação humana pode fornecer nova perspectiva sobre a relação com a biotecnociência, fortalecendo a capacidade descritiva da bioética; e, finalmente, prover novos instrumentos críticos que colaborem para sua função normativa.

A partir da chave interpretativa imunitária percebe-se que as temáticas bioéticas são aquelas em que o mecanismo de autoconservação humana é acionado ao mesmo tempo em que os atributos que qualificam e, em última instância, definem o humano estão em discussão. Consequentemente, compreende-se a função normativa da bioética a partir de um novo enfoque, ou seja, aquele de resistir a concepções humanas redutivas ao biológico e excludentes das diversidades sociais e culturais. Isto implica em uma análise moral que não se restringe aos riscos de biossegurança e ultrapassa a oposição entre transumanismo e bioconservadorismo ${ }^{36}$, porque permite incluir em seu escopo protetivo também o humano resultante das cumulativas ações interventivas e transformativas da tecnociência.

Como esforço de imunização, a bioética pretende exercer uma proteção que tenta alcançar a humanidade em seus dois sentidos: como característica que faz singular o indivíduo humano, e como coletivo dos homens. Os motores imunitários da biotecnociência, em seus objetivos e resultados sobre a transformação da humanidade, individual e coletiva, tornam-se assim questões bioéticas fundamentais. O horizonte imunitário é estratégico para identificar o que há de excludente nos sempre atualizados parâmetros para a autoconservação humana.

Encarar a disciplina a partir deste horizonte, no entanto, revela os desafios impostos à própria bioética enquanto mecanismo imunitário. Operar nessa membrana que ao mesmo tempo separa e comunica indivíduo e comunidade é a origem de muitos dos debates internos da disciplina. Esta perspectiva contribui para esclarecer, por exemplo, porque beirar o paternalismo é sempre o risco da proteção, bem como o fato da defesa da autonomia individual estar mais próxima do egoísmo ético do que se desejaria ${ }^{37}$.

A adoção do paradigma imunitário, como sistematização teórica sobre o ethos moderno, permite analisar as muitas antinomias que o constituem, entre vida e morte, indivíduo e comunidade, humano e não humano ${ }^{34}$. Esta compreensão oferece, por um lado, ferramentas adicionais para identificar e evitar as imunizações individuais que ocorrem às custas da comunidade inteira. Por outro, a bioética teria mais instrumentos para se opor a critérios excludentes de qualificação de vida e, então, resistir a transformações nos parâmetros de imunização que causem pressão no sentido de diminuir a diferenciação e, consequentemente, a singularidade humana.

\section{Referências}

1. Brody H. The future of bioethics. New York: Oxford University Press; 2009.

2. Dawson A. The future of bioethics: three dogmas and a cup of hemlock. Bioethics. 2010;24(5):21825.

3. Hedgecoe A. Bioethics and the reinforcement of socio-technical expectations. Soc Stud Sci. 2010;40(2):163-86.

4. Macklin R. The death of bioethics (as we once knew it). Bioethics. 2010;24(5):211-7.

5. Potter VR. Bioethics: bridge to the future. New Jersey: Prentice Hall; 1971.

6. Potter VR. From global bioethics: building on the Leopold legacy. In: Willers B, editor. Learning to listen to the land. Washington: Island Press; 1991. p. 157-62. 
7. Potter VR, Potter L. Global bioethics: converting sustainable development to global survival. Med Glob Surviv. 1995;2(3):185-91.

8. Reich WT. The word "bioethics": the struggle over its earliest meanings. Kennedy Inst Ethics J. 1995;5(1):19-34.

9. Beauchamp TL, Childress JF. The principles of biomedical ethics. New York: Oxford University Press; 1979.

10. Reich WT. The word "bioethics": its birth and the legacies of those who shaped it. Kennedy Inst Ethics J. 1994;4(4):319-35.

11. Ross LF. Forty years later: the scope of bioethics revisited. Perspect Biol Med. 2010;53(3):452-7.

12. Esposito R. Immunitas: protezione e negazione dela vita. Torino: Einaudi; 2002. p. 212.

13. Chambers T. Retrodiction and histories of bioethics. Med Humanit Rev. 1998;12(1):9-22.

14. Fox RC, Swazey JP. Observing bioethics. Oxford: Oxford University Press; 2008.

15. Sass HM. Fritz Jahr's 1927 concept of bioethics. Kennedy Inst Ethics J. 2007;17(4):279-95.

16. Goldim JR. Revisiting the beginning of bioethics: the contribution of Fritz Jahr (1927). Perspect Biol Med. 2009;52(3):377-80.

17. Zagorac I. Fritz Jahr's bioethical imperative. Synthesis Philosophica. 2011;51(1):141-50.

18. Muzur A, Sass HM. Fritz Jahr and the foundations of global bioethics: the future of integrative bioethics. Berlin: Lit Verlag; 2012.

19. Kopelman LM. Bioethics as public discourse and second-order discipline. J Med Philos. 2009;34(3):261-73.

20. Caplan AL, Arp R. Contemporary debates in bioethics. Oxford: Wiley-Backwell; 2013.

21. Ten Have HAMJ, Gordijn B. Handbook of global bioethics. New York: Springer; 2014.

22. Beck U. Risk society revisited: theory, politics and research programmes. In: Adam B, Beck U, Van Loon J, editors. The risk society and beyond: critical issues for social theory. London: Sage; 2000. p. 211-29.

23. Jonsen AR. The birth of bioethics. Oxford: Oxford University Press; 1998.

24. Potter VR. Humility with responsibility. Bioethic for oncologists: presidential adress. Cancer Research. 1975; 35(9): 2.297-306.

25. Agamben G. L'aperto: I'uomo e l'animale. Milano: Bollati Boringhieri; 2002.

26. Agamben G. Homo sacer: il potere sovrano e la nuda vita. Torino: Einaudi; 1995.

27. Foucault M. II faut défendre la société: cours au collège de France (1975-1976). Paris: Seuil; 1997.

28. Schramm FR. Bioética, biossegurança e a questão da interface no controle das práticas da biotecnociência: uma introdução. Revista Redbioética. 2010;1(2):99-110.

29. Schramm FR. A bioética como forma de resistência à biopolítica e ao biopoder. Rev. bioét. (Impr.). 2010;18(3):519-35.

30. Foucault M. Histoire de la sexualité I: la volonté de savoir. Paris: Gallimard; 1976.

31. Esposito R. Bíos: biopolitica e filosofia. Torino: Einaudi; 2004.

32. Hardt M, Negri A. Empire. Cambridge: Harvard University Press; 2000.

33. Esposito R. Communitas: origine e destino della comunità. Torino: Einaudi; 1998.

34. Esposito R. Termini della politica: comunità, imunità, biopolitica. Milano: Mimesis; 2008.

35. Esposito R. Terza persona: politica della vita e filosofia dell'impersonale. Torino: Einaudi; 2007.

36. Bostrom N. In defense of posthuman dignitiy. Bioethics. 2005;19(3):202-14.

37. Garrafa V. Inclusão social no contexto político da bioética. Rev. Bras. Bioética. 2005;1(2):122-32.

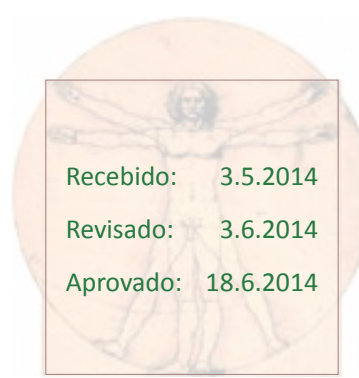

